\title{
Arbor
}

\section{El ingreso de España en la Organización Europea de Cooperación Económica*}

\section{Lorenzo Delgado Gómez-Escalonilla}

Arbor CLXX, 669 (Septiembre 2001), 147-179 pp.

El ingreso de España en la Organización Europea de Cooperación Económica y la puesta en marcha del Plan de estabilización fueron dos sucesos estrechamente asociados. La elaboración y aplicación de dicho plan jugó un papel esencial para franquear el acceso a aquella organización, a la vez que la intervención de la OECE resultó determinante en el cambio de la política económica española de finales de los años cincuenta. La España franquista, excluida en 1948 del Plan Marshall, iba a lograr incorporarse, con once años de retraso, a los mecanismos multilaterales impulsados por su principal instrumento de coordinación económica: la OECE. El precio fue la renuncia a los esquemas autárquicos y la politica de sustitución de importaciones que se habian promovido hasta entonces. El resultado fue la participación en uno de los períodos más dinámicos de crecimiento económico registrados en el continente europeo y una considerable aceleración del desarrollo económico del país.

En su número correspondiente al mes de julio de 1959 la revista Información Comercial Española contenía una carta a los lectores escrita por su director, Enrique Fuentes Quintana. Esa carta, publicada junto a un editorial que analizaba las razones y contenido del Plan de Es- 
tabilización, concluía con la siguiente afirmación: «lo que entraña el Plan de Estabilización es, a fin de cuentas, la posibilidad de situar la economía española en una nueva y robusta fase de desarrollo, capaz de alinear a nuestro país con Europa ${ }^{1}$. Sin duda el cambio de conducta que supuso el citado plan, abandonando definitivamente los esquemas autárquicos que habían prevalecido desde el final de la guerra civil, tuvo efectos muy importantes sobre la evolución posterior de la economía española. A partir de entonces, España se benefició de los efectos expansivos de uno de los períodos de crecimiento más rápidos que se ha producido en la economía internacional. Los procesos de apertura y modernización que puso en marcha la liberalización económica, aunque tuvieran un alcance más limitado de lo que hubiera sido deseable, han llevado a identificar el decenio de los años sesenta como el de la «revolución industrial española» ${ }^{2}$.

En una recapitulación efectuada años más tarde, también por Fuentes Quintana, se destacaban tres claves fundamentales para comprender por qué se produjo en aquellos momentos una reorientación económica de semejante calado. En primer lugar, se habían ido formando en años anteriores los cuadros de economistas que impulsaron el cambio de la política económica, desde sus puestos de responsabilidad en el Banco de España, el Ministerio de Hacienda y el Ministerio de Comercio. En segundo lugar, el deterioro de la situación económica puso en tela de juicio la continuidad de un modelo de desarrollo basado en una rígida política de sustitución de importaciones, máxime cuando a partir de 1957 la balanza de pagos se encontró en una crisis permanente agudizada a lo largo de 1959. Como tercer «y decisivo motivo» se señalaba el ingreso de España en los organismos internacionales (Organización Europea de Cooperación Económica, Fondo Monetario Internacional y el Banco Mundial), que proporcionó el respaldo necesario para la adopción final de las medidas estabilizadoras. Suele citarse en este sentido una frase del entonces ministro español de Comercio, Alberto Ullastres, que habría definido la estrategia del cambio económico en los siguientes términos: «la estabilización hay que hacerla en España desde el extranjero».

La conexión con los principales organismos económicos internacionales implicó tres aportaciones sustanciales:

«a) permitió explotar la condicionalidad de la ayuda (técnica y financiera) instada o prestada por esas instituciones al cumplimiento de una nueva política económica; b) ofreció una alternativa distinta -más influyente y menos arriesgada- para presentar las críticas internas a la vieja política económica realizada por los economistas de la Administración Pública (...); c) permitió obtener un asesoramiento técnico eficiente para 
El ingreso de España en la Organización.....

la definición y articulación de la política estabilizadora. La formulación final del programa de nueva ordenación económica contiene muchas propuestas y medidas en las que se incorporaron útiles consejos técnicos de los organismos internacionales» ${ }^{3}$.

\section{Colarse por las rendijas}

Desde que la II Guerra Mundial concluyó con la derrota de las potencias del Eje, la posición del régimen franquista en Europa se vió lastrada por su pecado original fascista. La frágil cohesión europea de la posguerrra, amparada en la experiencia de la lucha antifascista, no podía digerir con facilidad a un interlocutor que resultaba contra natura en aquellos momentos. La exclusión del European Recovery Program -el Plan Marshall- constituyó un temprano reconocimiento de los obstáculos que planteaba la reintegración en Europa de una España demasiado marcada por su pasado reciente. La guerra fría iba avanzando una escisión del continente que no se cerraría hasta varias décadas más tarde, pero todavía estaba fresco el recuerdo del combate contra el enemigo común, la camaradería de la resistencia y la liberación. Las fuerzas de la izquierda moderada, pilar básico para la política de contención del comunismo en Europa occidental que daba sentido último al Plan Marshall, no podían permitirse el lujo de aparecer asociadas a la dictadura franquista, ni tampoco querían hacerlo. Si, más allá de su componente anticomunista, la ayuda norteamericana era presentada como una contribución en defensa de la libertad y la democracia, ¿como encajar en el guión al régimen político español? ${ }^{4}$

Así pues, cuando Europa occidental iniciaba el camino hacia la convergencia económica, España quedó fuera del proceso. $\mathrm{Ni}$ se benefició de la financiación norteamericana, ni formó parte de los circuitos multilaterales que puso en marcha la Organización Europea de Cooperación Económica (OECE) desde su creación en abril de 1948, fortalecidos con el establecimiento de la Unión Europea de Pagos (UEP) en 1950. También se quedó al margen de otros hitos decisivos de la integración continental en este ámbito, como la creación de la Comunidad Europea del Carbón y el Acero en 1951, y del Euratom y la Comunidad Económica Europea en 1957. Pero para entonces ya se percibían muestras de una mayor receptividad entre los países de Europa occidental hacia la integración de España en sus esquemas de actuación ${ }^{5}$.

El cambio de gobierno que se produjo en España en julio de 1951 favoreció la adopción de una línea de política económica, todavía incipiente, que pretendía introducir nuevos criterios de gestión económica 
en el sector público y en el privado, y que buscaba al mismo tiempo disminuir las restricciones intervencionistas y proteccionistas que obstaculizaban la actividad productiva. La nueva actitud se vio robustecida por los Pactos firmados con Estados Unidos en septiembre de 1953, que incluían recomendaciones dirigidas a promover la estabilidad monetaria y financiera, y la flexibilización de los controles que regulaban los mercados interior y exterior. La ayuda norteamericana fue vital para sortear algunos de los estrangulamientos que atenazaban a la economía española, e hizo posible la importación de bienes de consumo, materias primas, bienes de equipo e inversiones, que permitieron acabar con el racionamiento y colaboraron en la modernización parcial de los equipos productivos. Las negociaciones con la misión americana también contribuyeron a que un sector de los cuadros de la administración española comenzase a familiarizarse con los nuevos métodos de planificación y gestión económica que manejaban sus interlocutores.

Los acuerdos suscritos con Estados Unidos significaron además la entrada de España en el redil occidental, aunque fuera por la puerta de servicio. El escenario internacional de mediados de los años cincuenta era distinto al de la segunda mitad de los años cuarenta. Los dos bloques políticos, militares y económicos eran ya una realidad que, por lo que afecta a Europa, había consumado la separación de los países del continente. El aval norteamericano era una carta de presentación a la que no resultaban insensibles los países de Europa occidental, sin que ello implicara que se vencieran de golpe las resistencias que aún suscitaba la aceptación del régimen franquista. Para erosionarlas, se siguió la misma estrategia que se había venido aplicando desde principios de esa década en el entorno de la Organización de las Naciones Unidas: la incorporación paulatina a organismos de carácter técnico.

El planteamiento de los dirigentes del régimen español era establecer cabezas de puente en materias menos sensibles políticamente, que proporcionaran un medio de acceso indirecto a las principales instituciones europeas. Así, se propició una acercamiento en sectores de segundo orden, como la agricultura, la alimentación, los transportes o las relaciones culturales ${ }^{6}$. Esa pauta de acción permitía tantear el terreno, ir buscando afinidades y argumentos para situar la participación española en niveles más elevados, y realizar esa aproximación sin arriesgarse a desaires internacionales como los sufridos al quedar fuera del Plan Marshall o del Pacto del Tratado del Atlántico Norte. La eventual vinculación con la OECE suponía un área particularmente sensible. Por un lado, era una especie de asignatura pendiente tras la decepción que había supuesto la exclusión de la ayuda económica norteamericana. 
El ingreso de España en la Organización.....

Por otro, hacia los países que la formaban se canalizaba una parte sustancial de los intercambios comerciales de España con el exterior, y sus acciones tenían una considerable repercusión sobre la economía española.

La primera toma de contacto con la OECE se produjo con motivo del enlace establecido entre esta organización y la Conferencia Europea de Ministros de Transportes. España estaba ligada a esta última, pero no pertenecía a la OECE. A comienzos de abril de 1954 el Secretario General de la organización recibía una petición de la diplomacia española para que se examinara como conjugar ambas situaciones. La solución acordada fue la creación de un Comité de Enlace sobre esta materia, que quedó constituido en julio de ese año ${ }^{7}$.

En el curso de ese verano de 1954 tuvo lugar otra entrevista, entre una delegación española y responsables de la OECE, para tantear en que posición quedaría España tras la asunción por parte de la organización de las competencias del Green Pool, dado que España estaba integrada en este último. El tema se trató en una reunión oficiosa del Consejo de la OECE celebrada en octubre, en la que se discutió sobre la fórmula de participación de España en las instancias de los organismos agrícolas. Los delegados de Portugal, Gran Bretaña y Suiza mostraron una actitud receptiva hacia España, en tanto que los de Bélgica y Noruega optaron por una postura dilatoria. En el mes de noviembre ya estaba preparada una propuesta de resolución, que determinaba que España se incorporaría en pie de igualdad a los trabajos del Comité Ministerial de Alimentación y Agricultura y al Comité de Suplentes, y dispondría además de un observador en las sesiones de otro conjunto de Comités técnicos cuando se abordaran cuestiones de aquella índole -Comité Económico, Comité Mixto de Intercambios y de Pagos Intraeuropeos, Comité de Intercambios, Comité de Pagos Intraeuropeos, Comité de Mano de Obra, Comité de la Madera, Comité de Textiles, Comité de Productos Químicos y Comité de Productividad e Investigación Aplicada-. Su aprobación como decisión del Consejo se demoró hasta mediados de enero de 1955. El día 28 de ese mes se firmaba el acuerdo entre la OECE y España ${ }^{8}$. En el mes de marzo, España ya contaba con una delegación permanente cerca de la $\mathrm{OECE}^{9}$. Para materializar esa vinculación inicial con la OECE se había dispuesto del soporte norteamericano, que intentó allanar también la participación española en los proyectos de la Agencia Europea de Productividad ${ }^{10}$.

La iniciativa del acercamiento partió del gobierno español. Sus dirigentes apreciaban que en la esfera europea se encontraban aún dificultades de aceptación que habían ido venciéndose en otros marcos territoriales. España estaba marginada del proceso de integración eu- 


\section{Lorenzo Delgado Gómez-Escalonilla}

ropea que tomaba forma en organismos políticos, económicos, militares y culturales. Si se había recuperado terreno en otros ámbitos internacionales gracias a la colaboración de los países hispanoamericanos y árabes, y al apoyo a veces determinante de Estados Unidos, en Europa no se disfrutaba de un clima de comprensión equivalente.

«Es pues indudable que el ingreso de España en un organismo como la OECE -de carácter intergubernamental y que por lo tanto no lleva aneja ninguna cesión de soberanía- representaría un importante éxito político, ya que daría a nuestro país un pleno «status» en el movimiento de integración europeo y precisamente dentro de la modalidad intergubernamental que parece la más conveniente. Nuestra participación en la OECE serviría de contrapeso a la hostilidad con que se nos ve en el organismo europeista parlamentario que es el Consejo de Europa y además nos facilitaría el ulterior acceso a las instituciones europeas hoy en estudio ...."11.

A los beneficios de índole política cabía añadir obviamente los de naturaleza económica, como habían advertido las autoridades comerciales españolas que comenzaron a analizar los requisitos que planteaba la eventual entrada en la OECE ${ }^{12}$. No obstante, se recomendaba actuar con prudencia. Sólo convenía tomar ese camino cuando se estuviera en condiciones de cumplir con las obligaciones que implicaba. El status que acababa de adquirirse en la OECE colocaba a España en una buena posición para elegir cuando dar un paso de mayor envergadura en su política europea. Entretanto, la presencia española en otras instancias de la organización fue incrementándose lentamente durante la segunda mitad de 1955. Se integró en el Comité del Petróleo, interesado en que España participara en el estudio sobre investigación y explotación del petróleo bruto y el gas natural, y contó con un observador en el Comité de Cueros y Pieles ${ }^{13}$. Muy pronto, no obstante, iba a darse un paso más allá.

\section{Un sondeo para conocer las posibilidades de admisión}

En noviembre de 1955 el gobierno español decidió sondear con mayor profundidad la acogida que podía encontrar una demanda de ingreso en la OECE. Se notificó de forma extraoficial y confidencial a su Presidente -Sir Hugh Elis Rees- que España deseaba asociarse más estrechamente a la organización, y que consideraba incluso la posibilidad de solicitar en un plazo bastante próximo su admisión como miembro de pleno derecho. Ante esa eventualidad, y para continuar 


\section{El ingreso de España en la Organización.....}

con la tramitación discreta del asunto, se convocó una reunión oficiosa de los jefes de las delegaciones a principios del mes de diciembre.

En el curso de la reunión, el Presidente de la OECE indicó que España había expresado su deseo de «no permanecer al margen del movimiento actual hacia el liberalismo» -es de suponer que económico-, y que la adhesión necesitaría una larga preparación pues aquel país debía cumplir una serie de condiciones fundamentales. Antes de tomar ninguna decisión procedía realizar un examen de la situación económica española, para lo cual se proponía el envío a aquel país de una misión encargada de recopilar y analizar las informaciones suministradas por las autoridades españolas. El Consejo se reservaría su posición hasta contar con ese informe detallado. No obstante, como primera medida que podía tomarse inmediatamente para que España conociera mejor las actividades de la organización, sugería otorgarle un estatuto de observador general. El principal frente de apoyo a esas recomendaciones lo constituían Gran Bretaña, Portugal, Alemania, Suiza, Italia e Irlanda, que defendían la aplicación de criterios estrictamente económicos. Bélgica y Luxemburgo se pronunciaban negativamente sobre la cuestión, mientras que otros países manifestaban una aceptación matizada -Francia, Noruega, Suecia, Dinamarca-. En cualquier caso, los jefes de delegación dieron una acogida inicial mayoritariamente favorable tanto a la posibilidad de conceder el nuevo estatuto de observador, como al acuerdo de principio para la admisión posterior de España en la OECE, tras un estudio de su situación económica y previo cumplimiento de las obligaciones contenidas en el Código de Liberalización de $1948^{14}$.

El asunto, a petición belga, fue llevado a la primera reunión oficial del Consejo celebrada en enero de 1956. En ella se debatieron tres cuestiones básicas: conocer si algún país miembro se oponía, por un motivo de carácter general, a que España fuese admitida en la organización tras aceptar una serie de condiciones económicas; saber si se estaba de acuerdo en efectuar un examen de la situación de la economía española, para analizar si podía y deseaba asumir las obligaciones que implicaba la integración en la OECE; por último, determinar si procedía otorgar a España el estatuto completo de observador en todos los comités plenarios, para que aquel país tuviera una noción más precisa de las consecuencias que implicaba una eventual adhesión. La casi totalidad de las delegaciones dieron su aprobación a las tres propuestas, tan sólo el representante belga se escudó en que no había recibido nuevas instrucciones de su gobierno para impedir que fueran adoptadas por unanimidad. Además, planteó si el gobierno español había solicitado de forma oficial la realización de ese informe oficioso 
encaminado a establecer las bases para la posterior admisión en la OECE, pregunta que respondió afirmativamente el presidente del Consejo. La decisión final se aplazó a una reunión posterior.

En el mes de febrero, Bélgica se mostró dispuesta a aceptar que la OECE llevase a cabo un estudio oficioso de la economía española, pero en contrapartida señaló que prefería que aún no se concediese a España el estatuto de observador pleno. En esa postura encontró entonces el respaldo francés, cuyo gobierno acababa de modificarse. Para ambos países la concesión del estatuto de observador pleno podría ser un "premio de consolación" si se rechazaba finalmente la admisión. A finales de ese mismo mes, el gobierno español hacía gestiones ante los gobiernos de la OECE para solicitar su acuerdo en torno a tres puntos: una declaración de que no existía ninguna objeción política a una eventual entrada de España a la OECE, la creación de un grupo de trabajo que estudiase las modalidades técnicas del ingreso, y la ampliación inmediata de su estatuto de observador. Por el momento, tuvieron que conformarse con la realización del informe económico oficioso a cargo del Grupo de Trabajo $\mathrm{n}^{\circ}$. 11, cuyos cometidos y composición quedaron fijados a mediados de marzo ${ }^{15}$.

Las reuniones del Grupo de Trabajo comenzaron a finales de abril, dirigiéndose a la delegación española un cuestionario con preguntas sobre la estructura y desarrollo de su economía y sobre la política seguida por el gobierno, junto a una exposición sumaria de las principales obligaciones que incumbían a los países miembros para ayudar a las autoridades españolas en la orientación de sus respuestas. La colaboración española en esa tarea sería posteriormente destacada por el Grupo de Trabajo. Por otro lado, pocos días antes de que el informe fuera presentado al Consejo de la OECE, su presidente recibía una carta de la Misión Permanente española comunicándole oficialmente el deseo de incorporarse como miembro de pleno ejercicio de la organización. Pero, conscientes de que las condiciones de la economía española impedían todavía la aceptación de las obligaciones que ese compromiso llevaba asociadas, se solicitaba encontrar una fórmula que permitiera ir asumiéndolas de forma progresiva. En tal sentido, se mostraba una absoluta disponibilidad para buscar una asociación más estrecha y una participación más completa en los trabajos de la OECE. Incluso se sugería que la UEP autorizase la transferibilidad de un cierto porcentaje de los medios de pago, lo que posibilitaría que España aplicase una política comercial más liberal ${ }^{16}$. Por entonces, según el informe del Grupo de Trabajo que comentaremos a continuación, el porcentaje español de importaciones de la zona OECE era del 59\%, 


\section{El ingreso de España en la Organización.....}

el de sus exportaciones a la misma zona era del 64\%. Ese bloque económico suponía el principal suministrador y cliente de los intercambios comerciales españoles.

El Grupo de Trabajo presentó su informe el 17 de julio. Era el primer análisis de la situación económica española efectuado por expertos de la OECE. Aunque sus autores reconocían que su evaluación resultaba insuficiente, sus resultados prefiguraban diagnósticos posteriores más elaborados sobre los problemas existentes. También se avanzaban ya las medidas que favorecerían la aproximación española a la organización ${ }^{17}$.

En su comparación con las economías de otros países miembros, la española era considerada poco desarrollada. El nivel de vida era insuficiente, el paro y sobre todo el sub-empleo eran considerables, la situación financiera interior y exterior eran precarias. Se precisaba mejorar las condiciones de la agricultura, aumentar las inversiones en el sector industrial, elevar la productividad y animar las inversiones extranjeras. Las autoridades españolas habían fomentado vastos programas de inversión e industrialización recurriendo al endeudamiento financiero interior, que acompañados de una expansión paralela del crédito privado habían generado una espiral inflacionista. Los métodos aplicados para contenerlo, basados en el control directo sobre los precios, los salarios y el comercio exterior, se habían demostrado ineficaces. La situación creada requería llevar a cabo una política anti-inflacionista vigorosa con la adopción de medidas fiscales y monetarias, actuando además sobre las restricciones que pesaban sobre la balanza comercial. Esta última sufría la constante presión de la incapacidad de los ingresos de las exportaciones para satisfacer las necesidades de importación. La ayuda americana paliaba hasta cierto punto el desequilibrio de la balanza comercial, que se regulaba por una red de acuerdos bilaterales y por un sistema de control estatal de exportaciones e importaciones. Toda transacción internacional, de mercancías o capitales, requería autorización oficial. A las licencias de exportación e importación se sumaba un complejo y discriminatorio sistema de cambios múltiples, si bien las autoridades españolas acababan de tomar medidas para reducir el número de tipos de cambio y pretendían abandonarlo en el futuro. Sin embargo, para alcanzar el equilibrio exterior era requisito esencial afrontar previamente el problema de la inflación interior.

El informe consideraba en suma que no era previsible, en un plazo breve, que España cumpliera integralmente o en una proporción importante las obligaciones de liberalización que incumbían a los miembros de la OECE. Se indicaba que España podía adoptar varias iniciativas, 
si su situación financiera interior no se agravaba, para encaminarse hacia esa vía: incrementar las medidas de liberalización sobre todo de los productos básicos; dar a la política de importación un carácter multilateral, remplazando en una primera etapa los contingentes bilaterales por contingentes globales; y considerar también la liberalización de algunas transacciones invisibles. Añadía que sería deseable llegar a una unificación de los tipos de cambio aplicables a las transacciones comerciales. Además, reconocía que la reglamentación bilateral de las importaciones era consecuencia de la precariedad de la balanza de pagos, de la falta de divisas y de la imposibilidad -salvo algunas excepcionesde hacer convertibles sus ingresos en el cuadro de los acuerdos bilaterales de pagos.

Ante la cuestión de cómo asociar más estrechamente a España a los trabajos de la organización, se esbozaban dos posibles soluciones. Según la primera, podía llegarse a un acuerdo especial con España para que participara en el examen económico anual, en los trabajos de los Comités verticales y en la Agencia Europea de Productividad, preparándola así para una progresiva adecuación a las normas de la OECE, e induciéndola a asumir una política de importación no discriminatoria respecto a sus miembros y una multilateralización de los ingresos españoles de divisas procedentes de la zona UEP. La segunda solución era la admisión en calidad de miembro de pleno derecho, acogiéndose durante bastante tiempo a las clausulas de salvaguardia del Código de Liberalización, lo que plantearía problemas para su participación en la UEP y requeriría un régimen especial en ésta y otras materias.

El informe se debatió en la sesión del Consejo del día 31 del mismo mes. La mayor parte de las delegaciones se decantaban por la primera de las soluciones propuestas por el Grupo de Trabajo, pero se acordó dar un plazo de reflexión hasta pasado el paréntesis estival. Los escollos más fuertes a una actitud receptiva hacia España continuaban procediendo de Bélgica y Francia, aunque esta última fuera adoptando poco a poco una posición más conciliadora. Una nueva reunión del Consejo celebrada a principios de octubre volvía a tratar el tema. Las delegaciones de Alemania, Dinamarca, Italia, Noruega, Suecia, Gran Bretaña, Irlanda, Suiza, Canadá y Francia propusieron una asociación progresiva de España a los trabajos de la OECE. Las delegaciones de Austria, Portugal, Estados Unidos y Turquía expresaban su preferencia por la admisión de España como miembro de pleno derecho, pero aceptaban la opción mayoritaria anterior. Las delegaciones de Bélgica y Luxemburgo carecían, una vez más, de instrucciones de sus gobiernos. También se planteó de nuevo la concesión de un estatuto 
El ingreso de España en la Organización.....

de observador general, y se acordó la preparación de un proyecto de resolución sobre el procedimiento a seguir para entablar negociaciones con España y el marco de las mismas.

La resolución definitiva, adoptada a fines de octubre tras dos nuevas reuniones y con una redacción más restrictiva, determinaba la creación de un Grupo de Trabajo ( $\mathrm{n}^{\circ}$. 18) que elaboraría y sometería al Consejo propuestas para establecer las condiciones de una eventual asociación. Tras su aprobación se discutirían con un representante del gobierno español. Se sugería que abordaran preferentemente las cuestiones de intercambios y pagos, y la participación de España en el examen económico anual y en las actividades de algunos Comités técnicos. La extensión del estatuto de observador, uno de los principales objetivos españoles en aquellos momentos, volvía a postergase ${ }^{18}$.

Los dirigentes políticos españoles, por su parte, parecían inclinados entonces a acelerar su ingreso como miembro de pleno derecho de la organización. En esos meses finales de 1956 se habían dirigido a Estados Unidos para solicitar una serie de facilidades crediticias, además de una ayuda económica directa de unos 200 millones de dólares, que permitirían a España hacer frente de modo inmediato a los desequilibrios que pudiera acarrear su entrada en la OECE. La gestión ante Estados Unidos no tuvo éxito. Los propósitos de las autoridades españolas no inspiraban excesiva confianza a sus interlocutores norteamericanos, dado que apenas habían tomado en consideración sus recomendaciones para liberalizar su política económica, se resistíąn a la unificación de cambios, a la flexibilización en materia de inversiones extranjeras, e incluso a integrarse en el Fondo Monetario Internacional (FMI). Idéntica respuesta encontrarían un año más tarde los nuevos responsables españoles de la diplomacia y el comercio exterior, cuando volvieron a transmitir al embajador norteamericano otra petición de obtener un respaldo económico excepcional para incorporarse a la $\mathrm{OECE}^{19}$. Las negociaciones con esta organización proseguirían al ritmo que ella marcaba, sin que del lado español se estuviera en condiciones de forzar la máquina.

\section{La aproximación se concreta: el acuerdo de Asociación}

Antes de acabar 1956 el presidente del nuevo Grupo de Trabajo daba cuenta de los progresos realizados. En primer lugar, se acudió al jefe de la delegación española, Argüelles, para tener una idea más precisa de hasta dónde estaban dispuestas a llegar las autoridades de su país. España tenía entre sus objetivos la liberalización de los intercambios y la simplificación del régimen de tipos de cambio, siempre 
que no incidieran negativamente en la deteriorada balanza de pagos. Había que convencer a su gobierno de que los pasos hacia la liberalización y la multilateralización serían favorables para su economía. Por otro lado, España deseaba participar en las tareas del mayor número posible de instancias de la organización, y estaba dispuesta a colaborar en la realización del informe económico anual suministrando las informaciones necesarias.

Tras esas conversaciones se acordó que los miembros del Grupo de Trabajo fueran a Madrid en enero de 1957 para entrevistarse con los ministros de Asuntos Exteriores, Hacienda, Comercio e Industria y con el Gobernador del Banco de España. El viaje se concebía como,una toma de contacto para crear un clima favorable. Le sucedería una segunda misión de expertos, encargada de definir con mayor precisión las obligaciones que España podía comprometerse a suscribir. El presidente del Grupo realizaba además dos observaciones. En la primera se pronunciaba por la concesión a España del estatuto de observador de pleno derecho, aunque consideraba oportuno aplazar tal medida hasta que las discusiones de fondo estuvieran más avanzadas. La segunda era una sugerencia para que España se incorporase al Comité del Petróleo, que interesaba especialmente a su gobierno desde el comienzo de la crisis de Suez. Esta última propuesta se aceptó rápidamente ${ }^{20}$.

Al desplazamiento a Madrid de la misión exploratoria le siguió a mediados de febrero de 1957 el viaje a París del ministro español de Comercio, Manuel Arburúa, para asistir como observador a las sesiones plenarias de la OECE. Arburúa había sido el principal defensor en el Consejo de Ministros de la asociación con aquel organismo. A finales de ese mes, como consecuencia del cambio de gobierno que tuvo lugar en España, Alberto Ullastres se hacía cargo de la cartera de Comercio. El nuevo ministro iba a continuar el proceso emprendido por su predecesor, con el apoyo de sus colegas de gabinete Mariano Navarro Rubio -Hacienda- y Fernando Castiella -Asuntos Exteriores-. La renovación de los cuadros directivos de esos ministerios, junto al concurso prestado desde el Banco de España, iban a agilizar la formulación de una nueva política económica y el entendimiento con los organismos internacionales, cuyo respaldo fue vital para su cristalización.

El gobierno nombrado en 1957 debió afrontar una coyuntura caracterizada por la intensificación de las tendencias integradoras entre los países europeos occidentales y por la profundización de sus interdependencias económicas. En el mes de marzo el Tratado de Roma establecía la Comunidad Económica Europea (CEE). En respuesta, e impulsado por Gran Bretaña, se constituía en el seno de la OECE 


\section{El ingreso de España en la Organización.....}

un Comité Intergubernamental para estudiar la creación de una zona europea de libre comercio. Por el momento, el gobierno español perseveró en la vinculación con la OECE, que se ajustaba mejor a sus objetivos, aunque sin dejar de prestar atención a la evolución de los otros movimientos de integración económica. A finales de julio se constituyó una Comisión Interministerial para el estudio de los problemas que pudieran derivarse tanto del funcionamiento del Mercado Común, como de una eventual Zona de Libre Comercio y de la Energía Atómica. $\mathrm{Su}$ actividad fue escasa.

Para entonces, la misión técnica de la OECE se había desplazado a España y había mantenido durante el mes de abril largas entrevistas con altos cargos de Hacienda, Comercio y el Banco de España. Pese a la insuficiencia de las estadísticas españolas y la dificultad de realizar un análisis de su situación económica, los miembros de la misión destacaban la franqueza con que los representantes españoles habían respondido a todas sus cuestiones y su absoluta disponibilidad para suministrarles todas las informaciones de que disponían. En su informe, presentado en el mes de junio, subrayaban el recrudecimiento de las presiones inflacionistas, provocadas por el incremento simultáneo de la demanda y los costes. El aumento de la circulación monetaria no había sido compensado por el crecimiento de la producción. La repercusión de esas presiones inflacionistas interiores sobre la balanza de pagos se intentaban limitar mediante las restricciones cuantitativas de las importaciones, pero además de las distorsiones que ello provocaba la caída a un nivel muy bajo de las reservas de oro y divisas demostraba que el mecanismo no funcionaba. Las autoridades españolas habían recurrido a medidas fiscales y monetarias para yugular la inflación, y habían reconducido el sistema de cambios múltiples a un cambio único devaluado. Sin desestimar la importancia de las medidas tomadas, la misión consideraba que no lograrían eliminar a corto plazo las dificultades internas y externas de la economía española. También estimaba que las perspectivas de la balanza de pagos se presagiaban extremadamente difíciles, cuando menos en el curso de aquel año.

En la panorámica que trazaban sobre la capacidad española para asumir las obligaciones como miembro de la OECE su dictamen era categórico: era casi imposible mientras que el equilibrio económico no fuera más sólido y duradero. Era evidente que las autoridades españolas querían estrechar los lazos económicos con el mundo exterior: se habían unificado las tasas de cambio como había aconsejado el anterior informe de la OECE; se tenía intención de aplicar un porcentaje de liberalización comercial del $31 \%$ a los países miembros de la organización -en lugar 


\section{Lorenzo Delgado Gómez-Escalonilla}

del $9 \%$ entonces existente-; se deseaba establecer contingentes globales que cubrieran una parte sustancial del resto de la importaciones privadas, e incluso se proyectaba una liberalización parcial de las transacciones invisibles. La misión estaba muy sorprendida por la voluntad de las autoridades españolas de ir tan lejos como fuera posible en la vía de la cooperación económica según las pautas de la OECE.

Para afianzar esa conducta se recomendaba a los países miembros concluir nuevos acuerdos que estrecharan los vínculos institucionales entre España y la organización, y procurar que las relaciones de intercambios y de pagos de España con la zona UEP se reorientaran del bilateralismo al multilateralismo. La primera propuesta reiteraba llamamientos anteriores para intensificar la participación de España en las actividades de la OECE, en particular en sus estudios periódicos de coyuntura económica. La segunda, de mayor calado, contemplaba la necesidad de suministrar a España una ayuda importante para facilitar el restablecimiento de su equilibrio económico, e implicaba el desarrollo de negociaciones bilaterales para hacer transferibles en la zona UEP todos los ingresos españoles procedentes de los países miembros y para renegociar sus deudas bilaterales. Esas gestiones convenía organizarlas bajo los auspicios del Consejo, que también podría animar a los países que aún no lo hacían a que aplicasen a España las medidas de liberalización en vigor entre los miembros de la $\mathrm{OECE}^{21}$.

En el informe quedaban ya diseñadas las fases que atravesó la futura incorporación de España a la OECE. En la primera de las propuestas se avanzó más rápidamente, dado que para culminar la segunda se hacía preciso conciliar un conjunto de intereses diversos. Ambas formaban parte del proyecto de resolución sometido a la aprobación del Consejo en el mes de septiembre. El texto finalmente aprobado encargaba al Grupo de Trabajo que preparase junto al representante del gobierno español un proyecto de acuerdo institucional, y consideraba deseable que en esas negociaciones se abordase la sustitución del bilateralismo por el multilateralismo ${ }^{22}$.

En el mes de noviembre estaba preparado un plan de negociaciones sobre arreglos multilaterales de intercambios y de pagos. El gobierno español propondría un conjunto de convenios que se aplicarían a título experimental por un período de un año, especificando mercancías a liberar, países a los que afectaría, productos y cantidades que pasarían a contingentes globales, grado de multilateralización a adoptar en los pagos, etc. Sobre el programa español se realizaría un primer intercambio general de puntos de vista para aceptar sus líneas generales, y luego se entablarían negociaciones bilaterales para determinar las cuestiones particulares. ${ }^{23}$ 
El ingreso de España en la Organización.....

En cuanto al proyecto de acuerdo de asociación de España con la OECE se encontraba casi ultimado antes de concluir el año. El Consejo de Ministros español autorizó al titular de Asuntos Exteriores, en sus reuniones del 11 de julio y del 13 de octubre, a que negociara dicho acuerdo. Según la interpretación española, el acuerdo equiparaba su estatuto al que tenían Estados Unidos y Canadá, y se cubrían los objetivos institucionales que se había fijado el gobierno español a lo largo del período de negociación. España participaría, con voz consultiva, en todos los órganos en que no se aplicase la admisión restringida, podría intervenir en cualquier proyecto de la Agencia Europea de Productividad, y tomaría parte en los exámenes de coyuntura económica. Asimismo, suscribía los objetivos económicos de la organización y las obligaciones generales asumidas por sus miembros, y se esforzaría por ejecutarlas comprometiéndose a abolir, sin discriminación, las restricciones a los intercambios, las transacciones invisibles y las transferencias con los países de la OECE, en la medida que se lo permitiera su situación económica y financiera. Los países miembros adoptarían disposiciones análogas con respecto a España. Además, se invitaba al gobierno español a presentar un programa de multilateralización de los intercambios. El acuerdo de asociación se firmó el 10 de enero de 1958 y fue ratificado a mediados de abril ${ }^{24}$.

\section{La situación económica se agrava, los contactos con los organismos económicos internacionales se intensifican}

En paralelo a las negociaciones con la OECE, el gobierno español había comenzado a tomar una serie de medidas para mitigar las presiones inflacionistas interiores y los problemas cada vez más acuciantes de su balanza exterior. Las medidas monetarias y fiscales adoptadas en la segunda mitad 1957 mostraban que los dirigentes económicos españoles, por necesidad o por convicción, parecían dispuestos a introducir nuevos criterios de actuación más homologables con su entorno. Se suprimió el sistema de cambios múltiples, con una ligera devaluación de la peseta y el establecimiento de un cambio único, aunque la insuficiente actuación sobre la demanda interior y el alza de precios motivaron que rápidamente reaparecieran las primas y los retornos, lo que equivalía en la práctica a la vuelta al sistema anterior. Se congelaron los salarios de los funcionarios públicos. Se puso un tope al redescuento del Banco de España, se elevaron los tipos de interés y de descuento bancario, y se dieron instrucciones a la banca para cortar los créditos especulativos. Se creó una Junta para la revisión 
del Arancel de Aduanas. Se aprobó una reforma tributaria que permitió el aumento de la recaudación y la disminución del déficit público. Tales medidas si bien eran necesarias resultarían insuficientes, como ya habían previsto los expertos de la OECE y reiterarían en informes posteriores, pues no atajaban de raíz los problemas de la economía española ni preparaban el terreno para un desarrollo sustentado sobre bases sanas. Una opinión que también compartían las autoridades norteamericanas y que habían trasladado a sus colegas españoles, aconsejándoles una mayor decisión para afrontar una estabilización económica y un cambio de rumbo que incrementaría sus posibilidades de obtener financiación y asistencia de los organismos económicos internacionales ${ }^{25}$.

El proceso estaba en marcha, pero aún tardaría en consumarse. Mientras tanto, el gobierno español desplegaba sus esfuerzos diplomáticos para no quedar marginado una vez mas de otras iniciativas de interrelación económica que se debatían en Europa. La evolución del proyecto de zona de libre comercio era seguida con interés. Una agrupación de tales características, al no presentar condicionamientos políticos como ocurría con el Mercado Común, podía resultar una opción a considerar en el futuro. En diciembre de 1957 el gobierno español comunicó a sus homólogos europeos el deseo de ser invitado a participar en las reuniones del Comité Intergubernamental que abordaría esa materia. Se aducían motivos tanto económicos como políticos, que tenían por marco genérico su interés «por las cuestiones de cooperación europea». La respuesta fue postergada ante la oposición de los países del Benelux, expuesta en una reunión del Consejo de Ministros de la CEE a mediados de marzo de 1958 y que vinculaba al resto de sus miembros. El gobierno español reiteraba su solicitud en el mes de julio, alegando que el acuerdo de asociación suscrito con la OECE le otorgaba «títulos más que suficientes para ingresar automáticamente en el Comité Intergubernamental». Ante la insistencia española, y con el apoyo francés, su demanda volvió a plantearse en septiembre al Comité de Representantes Permanentes de la Comunidad, con idéntico resultado negativo. Finalmente, en noviembre de 1958, España obtuvo el estatuto de observador para participar en los trabajos del Comité26.

También se avanzó en otro terreno que estaba entre las preocupaciones fundamentales del gobierno español: la asociación a las instancias de la OECE encargadas de las cuestiones energéticas. Si ya se había accedido al Comité del Petróleo, el próximo objetivo era la Agencia Europea para la Energía Nuclear. Desde noviembre de 1957 se especulaba por parte española con la participación en el Grupo 
El ingreso de España en la Organización.....

Atómico y en la Sociedad Internacional «Eurochemic». El acuerdo de asociación facilitó que, en marzo de 1958, se sondease al Grupo de Trabajo sobre la receptividad que encontraría una demanda de vinculación a la Agencia Europea para la Energía Nuclear. En mayo la petición española se hacía oficial, y a finales de julio el Consejo de la organización aprobaba su participación. En el mes de octubre, el gobierno español comunicaba a la OECE su decisión de adherirse a la Convención sobre el establecimiento de un control de seguridad en el dominio de la energía nuclear y al Tribunal creado por la misma. Asimismo, se suscribía la Convención relativa a la constitución de la Sociedad Europea para el Tratamiento Químico de Combustribles Irradiados (Eurochemic) ${ }^{27}$.

Por otro lado, desde mediados de 1957 se habían mantenido conversaciones entre representantes españoles y del FMI para sondear las posibilidades de ingreso, que recibieron una acogida positiva. En diciembre de ese año, con motivo de la visita a España del Secretario de Estado norteamericano -John Foster Dulles-, éste insistía a sus interlocutores españoles sobre la conveniencia de reorientar su política económica y aseguraba, en una entrevista con el general Franco, que Estados Unidos apoyaría su acceso en el FMI y el Banco Internacional de Reconstrucción y Desarrollo (BIRD). En enero de 1958 se formuló la solicitud formal de ingreso. Aceptadas en abril por el gobierno español las condiciones determinadas por el Comité Ad Hoc encargado de examinar su demanda de adhesión, el Fondo de Gobernadores aprobaba la admisión en el mes de mayo. Tras cumplir con varios requisitos de índole jurídica, España se convertía el 15 de septiembre de 1958 en miembro del FMI y del BIRD. Esa incorporación ponía a su alcance el acceso a financiación y a asesoramiento técnico, que pronto sería requerido por las autoridades españolas. De hecho, ya en octubre de 1958 una misión del Banco Mundial enviada a España había diagnosticado la necesidad de una estabilización de la economía española ${ }^{28}$.

A lo largo de ese año también fue quedando patente que no bastaba con un reajuste de las condiciones del intercambio comercial exterior de España para solucionar los problemas de su economía. La negociación del plan de multilateralización comercial y de pagos con los países de la OECE, con validez prevista para un año, se desarrolló con bastante lentitud.

En marzo se llegó al acuerdo de que el porcentaje de productos liberalizados se incrementase del $8 \%$ al $15 \%$, y que el $75 \%$ del comercio con ese área que permanecía bajo cuotas bilaterales pasase al régimen de cuotas globales. España solicitaba, en contrapartida, obtener para sus exportaciones el mismo grado de liberalización que los países miem- 


\section{Lorenzo Delgado Gómez-Escalonilla}

bros se concedían entre sí, también deseaba el fin de las prácticas discriminatorias aún existentes. Los negociadores de la OECE consideraban que el proyecto podría ser efectivo para comienzos de julio. En el mes de abril, el ministro español de Asuntos Exteriores, con motivo de su presencia en París para conmemorar el $\mathrm{X}$ aniversario de la fundación de la OECE, anunciaba que el plan de multilateralización iba a ser propuesto «muy próximamente». Según el ministro, ese plan estaba llamado «a ser la clave de una nueva estructura del comercio exterior de España». Se pretendía que la totalidad de los intercambios españoles con aquel área económica tuvieran carácter multilateral $\mathrm{y}$, posteriormente, en la medida que lo permitiera la balanza de pagos y el nivel de abastecimiento del mercado interior, se extendería el régimen de liberalización sector por sector ${ }^{29}$.

Pasarían aún varios meses antes de que ese texto llegase a las instancias de la OECE. Entretanto, Navarro Rubio había presentado en el mes de junio al Consejo de Ministros un memorándum con las pautas del reajuste que era preciso realizar en el terreno económico, y que preludiaban la operación estabilizadora. Según el ministro, su aplicación no debía demorarse en exceso, ya que la situación de la balanza de pagos y la economía eran críticas. A la luz de tal situación, se autorizó que los ministros de Hacienda, Comercio y Asuntos Exteriores intensificasen sus contactos internacionales para concretar los pasos a dar en ese camino. En el transcurso de ese verano, los responsables de la misión económica norteamericana en España insistían sobre la necesidad de profundizar en la estabilización financiera y en el estímulo a las empresas privadas para acelerar el desarrollo económico. A su criterio, se hacía cada vez más urgente emprender una reorientación fundamental de la política económica española, entre otras razones porque se mantenía una fuerte dependencia hacia Estados Unidos y, en caso de cesar sus subsidios, se recrudecerían los problemas del régimen en este ámbito ${ }^{30}$.

El proyecto de acuerdo multilateral de comercio no fue enviado a la organización hasta mediados de agosto. Contenía una lista de productos y un memorándum explicativo, que pasaron a ser examinados por el Comité de la Dirección de Intercambios y el Comité de Dirección de la UEP. Un mes más tarde, el gobierno español completó su contenido mediante una nota que exponía sus demandas en materia de liberalización de sus exportaciones y multilateralización de sus medios de pago en la zona OECE. Para facilitar el tránsito desde el sistema bilateral a los nuevos esquemas comerciales se deseaba contar con un crédito multilateral rotativo, que enjugase los posibles desequilibrios 
El ingreso de España en la Organización.....

de pagos del período inicial. Una gestión equivalente en busca de ayuda financiera se dirigió hacia Estados Unidos, alegando de nuevo la exclusión española del Plan Marshall y, aunque ya no se dijera explícitamente, la oportunidad de obtener una compensación por aquella injusta marginación. Ahora, sin embargo, los términos eran más medidos, y se solicitaba tal ayuda para proceder a la ejecución de las medidas de liberalización comercial y financiera una vez que fueran acordadas con la OECE. Esa actitud, junto al reciente ingreso en el FMI, resultaban más acordes con las indicaciones norteamericanas para abordar una apertura económica, de ahí que Estados Unidos mostrase su disposición a cooperar en la asociación española con la OECE y a respaldar las propuestas que desarrollasen esa conexión. Las negociaciones sobre el plan de multilateralización continuaron a lo largo de aquel año, pasando de su estudio por parte de los organismos de la OECE a la consideración de cada uno de los países miembros, y devolviéndose después a las autoridades españolas para que realizaran una serie de reajustes técnicos. En los primeros meses de 1959 todavía seguía en discusión ${ }^{31}$.

Pero para entonces ese diseño de viraje comercial había sido sobrepasado por otros acontecimientos que determinarían una actuación más profunda y generalizada sobre la economía española. En los últimos días de 1958 se produjeron varios sucesos internacionales susceptibles de provocar efectos colaterales sobre la situación española. Se declaró la convertibilidad exterior de las principales monedas europeas y la disolución de la UEP, que dió paso a la entrada en vigor del Acuerdo Monetario Europeo. Los países del Mercado Común ampliaron los porcentajes de liberalización de su comercio exterior, con la reducción en un $10 \%$ de sus tasas aduaneras. El gobierno francés decidió devaluar el franco y acometer un plan de estabilización. El primero de los acontecimientos, sobre todo, provocó una especial preocupación entre los medios económicos españoles, ante la conciencia de que se ensanchaba la distancia entre España y el resto de Europa occidental.

El ministro español de Comercio, con objeto de frenar las especulaciones, realizó unas declaraciones afirmando que España no optaría por la devaluación de su moneda, como había hecho Francia. También anunció que el ingreso español en la OECE estaba cada vez más próximo: se habían presentado dos proyectos, uno de mercancías para la globalización de los intercambios y otro de pagos, y se aludía a un plan conjunto entre la OECE, el FMI y España que proporcionaría los medios para acelerar la liberalización de los intercambios. Sin embargo, según el ministro de Hacienda, era preciso ir más allá para allanar los obs- 
táculos hacia esa liberalización. En enero de 1959 presentó al Consejo de Ministros un memorándum sobre «Convertibilidad exterior de la peseta y estabilidad monetaria», que fijaba como objetivos de la política económica: devaluar la moneda a un cambio realista, actuar sobre los factores que impedían la estabilidad monetaria y obtener la convertibilidad de la peseta con la ayuda exterior ${ }^{32}$.

La necesidad de un tratamiento de choque de tales características, que permitiese encarar con ciertas garantías la agravación de la situación de la economía española, había sido puesta de relieve poco antes por otra misión de expertos de la OECE.

\section{El diseño del plan de estabilización y el ingreso en la OECE}

A mediados de diciembre de 1958 dos especialistas de la OECE se trasladaron a Madrid para completar las informaciones recogidas a lo largo del año con destino a la elaboración del primer examen anual oficial de la economía española. Las apreciaciones que realizaran debían servir también para encauzar el debate sobre el plan de comercio multilateral. En su dictamen subrayaban que el agotamiento gradual de las reservas de divisas durante ese año colocaba en una situación de precariedad al conjunto de la situación económica. Urgía un enderezamiento general que comprendiera la estabilización financiera interior y una reforma del sistema de intercambios y de pagos con el exterior. El control de la inflación resultaba imprescindible. La devaluación de la peseta era necesaria, pero no suficiente. Había que acabar sin más demoras con las manipulaciones de primas y tasas. También se hacía preciso liberar gran parte de las importaciones, para asegurar la regularidad de los suministros y terminar con los abusos a que daban pie las licencias. Todo ello debería acompañarse de una contribución financiera exterior para afrontar los riesgos más importantes derivados de la liberalización. Sus conclusiones quedaban sintetizadas con toda claridad en el curso de una reunión restringida que mantuvieron con los Presidentes y Vicepresidentes del Consejo y del Comité Ejecutivo de la OECE, a finales de enero de 1959.

«La impresión de los expertos del Secretariado sobre la situación económica y financiera de este país es actualmente bastante sombría. En su opinión, puede ponerse en cuestión si los esfuerzos hechos por España para integrarse poco a poco en la OECE tienen sentido, a la vista de esta situación. España no podría a su juicio asumir las obligaciones que incumben a los países miembros, siquiera fuese parcialmente, más 
que si se pusiera en marcha un plan de rectificación, susceptible de poner fin progresivamente al repliegue de la economía española sobre sí misma» ${ }^{33}$.

Según los expertos en cuestión, parecía delicado sugerir al gobierno español la aplicación de dicho plan, tanto más cuanto que requeriría para su realización una ayuda financiera por parte de los países de la OECE. En una conversación entre el ministro español de Comercio y su colega alemán, éste se había mostrado dispuesto a respaldar tal ayuda si el gobierno español daba pruebas inequívocas de su voluntad de reorientar su economía. Pero, siempre en opinión de los expertos de la OECE, cabía abrigar serias dudas a este respecto. Aunque existiesen en el gabinete español partidarios convencidos de la necesidad de ese cambio, nada indicaba que frente a los potentes intereses de signo contrario pudiese contarse con el apoyo total y constante del Jefe del gobierno. Para despejar esas incertidumbres se preveía el envío a España de una nueva misión, en coincidencia con la visita que realizaría al país otra misión del FMI, con objeto además de coordinar con este organismo cualquier posible actuación. La visita se aplazó por el momento ${ }^{34}$.

La conjunción de los acontecimientos internacionales y la penuria de divisas haría posible que cobrase fuerza el doble frente, exterior e interior, favorable al cambio económico. Estabilización, liberalización y reorientación económica eran mensajes que llegaban con insistencia creciente a los dirigentes económicos españoles desde Estados Unidos, el FMI o la OECE, y que se hacían cada vez más perentorios.

A mediados de febrero llegaba a Madrid la misión del FMI encabezada por el Director del Departamento de Europa -Gabriel Ferrás-, que cumplía así con las consultas establecidas por el artículo XIV de sus preceptos. La misión estaba autorizada también para tratar con funcionarios españoles sobre la reforma económica que resultaba conveniente poner en ejecución. Un primer cambio de impresiones sobre tal asunto ya se había producido meses atrás, en octubre de 1958, durante la reunión anual de la Junta de Gobernadores del FMI y del BIRD celebrada en Nueva Delhi. La importancia de la intervención del FMI se acrecentaba ante la ralentización de las gestiones para llegar a un acuerdo con la OECE. La misión se entrevistó con representantes de todas las ramas de la Administración Pública relacionadas con la economía, siendo recibida por los ministros de Hacienda y Comercio y por el Gobernador del Banco de España. En su informe reservado se mencionaba la preparación de un Plan de Estabilización destinado a detener la inflación, con medidas correctivas que el gobierno español pretendía aplicar en un futuro próximo ${ }^{35}$. 
El primer esquema del contenido de ese plan fue redactado por Ferrás y Juan Sardá -Director del Servicio de Estudios del Banco de España-, y se elevó a los ministros de Comercio, Hacienda y Asuntos Exteriores. Su desarrollo contemplaba una intervención global con acciones sobre la política monetaria y financiera interior, la política monetaria y comercial exterior, y una mayor apertura a la presencia de capitales extranjeros. En apoyo del plan se esperaba contar con la financiación del FMI, la OECE, el gobierno de Estados Unidos y la banca privada norteamericana ${ }^{36}$. Buena parte de las ideas recogidas en el documento venían siendo debatidas desde tiempo atrás entre los técnicos españoles y los expertos internacionales.

Antes de regresar a Estados Unidos, Ferrás se entrevistó con la plana mayor de la OECE para relanzar el diálogo entre España y la organización, ya con el horizonte puesto en el futuro Plan de Estabilización. Ese nuevo enfoque iba a encontrar un eco positivo, en la medida que coincidía con el dictamen formulado por los expertos de la OECE. No obstante, la organización evitaba aún pronunciarse sobre una eventual concesión de ayudas o la admisión de España entre sus miembros. Tal y como había acordado su Consejo, tomaba nota de la preparación del plan y estaba dispuesta a proporcionar ayuda técnica para su diseño. Una misión oficiosa se encargaría inicialmente de esa labor ${ }^{37}$.

Sobre la base del documento elaborado por Ferrás y Sardá trabajó una comisión técnica española en colaboración con sendas misiones de expertos del FMI y de la OECE, que se desplazaron a España entre finales de abril y principios de mayo. Fruto de esos contactos fue la realización de un borrador de memorándum destinado a las organizaciones internacionales, con el deseo de obtener su concurso en la estabilización y la liberalización de la economía española. El proceso se acometería mediante un conjunto de medidas desplegadas en varios ámbitos: sector público, política monetaria, precios y comercio interior, liberalización del comercio y de los pagos, e inversiones extranjeras y amnistía para la repatriación de capitales. Con ellas se esperaba alinear la economía española con la del resto de los países del mundo occidental. Desde Washington se puso en conocimiento de los dirigentes de la OECE el respaldo que prestaban a ese programa ${ }^{38}$.

Al tiempo que se iban perfilando los ejes de la reorientación económica en ciernes, el gobierno español tomó la decisión, a mediados de mayo, de notificar a la OECE su intención de convertirse en miembro de pleno derecho de la organización. Para cumplir con las obligaciones de esa integración se exponían las grandes líneas del Plan de Estabilización en cuya elaboración se estaba trabajando. Asimismo, se so- 
El ingreso de España en la Organización.....

licitaba el envío de una misión que participase en la confección definitiva del plan, a fin de ajustarse a las condiciones requeridas para acceder a la OECE. La organización aceptó dicha propuesta y decidió que la misión viajase a España en el mes de junio, contando entre sus miembros al Secretario general, a los Presidentes del Comité Director del AME, del Comité de Dirección de Intercambios y del Comité de Suplentes, junto a otros altos funcionarios de la OECE. Su actuación se desarrollaría en coordinación con la de los representantes del $\mathrm{FMI}^{39}$. El Consejo de Ministros español, por su parte, discutía el borrador del memorándum en su reunión del 1 de junio. Las conversaciones con las organizaciones internacionales iban por delante, en ocasiones, del propio debate en el gabinete español. A éste se le ofrecían los resultados de las gestiones con el refuerzo que suponía el aval de aquellas, de forma que resultaba más difícil para los sectores reticentes oponerse al cambio de orientación económica.

Las conversaciones se sucedieron durante el mes de junio en Madrid, París, Washington, Basilea y Nueva York, entre representantes del gobierno español, el FMI, la OECE, el Banco de Pagos Internacional y la banca privada norteamericana. Los últimos retoques se dieron en la capital española, donde coincidieron en los últimos días de junio las misiones de alto nivel del FMI y la OECE. A las visitas tradicionales a los altos responsables de la política económica se añadió una entrevista con el Jefe del Estado, que despejó los obstáculos todavía existentes sobre la nueva paridad de la peseta con respecto al dolar. Las autoridades españolas transmitían a sus interlocutores internacionales su firme decisión de sanear la situación económica del país, eliminar los factores internos de inflacción y normalizar el régimen de comercio y de pagos exteriores. Las misiones de ambas organizaciones concretaron junto con los dirigentes españoles los detalles del programa a aplicar, cuya evolución sería examinada de forma conjunta antes de terminar el año. Según la conclusión general del informe elaborado por la misión de la OECE, «el Programa de Estabilización del Gobierno español debería permitir a España asumir progresivamente las obligaciones que implica la plena participación en la OECE» y, al mismo tiempo, «la adhesión de España a la OECE y al AME contribuirá al éxito del programa de estabilización ${ }^{40}$.

El 30 de junio se aprobó la versión final del memorándum dirigido al FMI y a la OECE. El gobierno español proclamaba que «había llegado el momento de reorientar la política económica con el fin de situar la economía española en línea con los países del mundo occidental y liberarla de intervencionismos que, heredados del pasado, no se ajustan 


\section{Lorenzo Delgado Gómez-Escalonilla}

a las necesidades de la situación actual». Para lograrlo, el plan que se pondría en marcha tenía como objetivos: estabilizar los gastos del sector público y reducir su déficit global; asignar un límite para la expansión del crédito bancario al sector privado; suprimir progresivamente los controles interiores sobre los precios; fijar una nueva paridad de la peseta de acuerdo con el FMI y abolir el sistema de cambios múltiples; liberalizar una proporción notable de las importaciones y globalizar la mayor parte de los contingentes restantes, favoreciendo la multilateralización gradual del comercio y de los pagos con el exterior; introducir una legislación más liberal en materia de inversiones extranjeras; conceder una amnistía de seis meses para la repatriación de los capitales españoles en el extranjero, y dotar de una mayor flexibilidad al sistema económico. El documento se acompañaba de anexos que especificaban como afectaría a los distintos países y productos el nuevo régimen de intercambios con el exterior, materia que fue objeto de una notificación complementaria que cifraba en torno al $50 \%$ el porcentaje de las importaciones liberalizadas procedentes de los países de la OECE y de la zona dólar ${ }^{41}$.

En las primeras semanas de julio emitían su dictamen sobre ese memorándum los principales órganos de la OECE, determinándose los plazos de aplicación de las diferentes medidas y preparándose los proyectos de decisión que convertirían a España en miembro de la organización. Asimismo, se acordó que el Fondo Europeo destinaría una suma de 100 millones de dólares a respaldar la ejecución del Plan de Estabilización ${ }^{42}$. Junto a esa aportación del Fondo Europeo, el apoyo financiero exterior comprendería, en los términos en que se presentó a la opinión pública: 75 millones del FMI, 45 millones procedentes de la consolidación de deudas bilaterales con los gobiernos de la OECE, en torno a 70 millones de la Banca privada norteamericana, y 130 millones de asistencia del Gobierno de Estados Unidos a través de diversos programas, más los fondos de contrapartida disponibles en pesetas. La realidad es que se habían agrupado ayudas, créditos y compromisos anteriores de carácter heterogéneo para dar una imagen más sólida de la confianza internacional en la viabilidad del plan. El gobierno estadounidense, que fue informado periódicamente de las gestiones realizadas y a quien se entregó el texto definitivo del plan antes de cursarlo oficialmente a las organizaciones internacionales, prestó su apoyo político e incluso hizo valer su influencia para la concesión de los préstamos de la OECE y el FMI. Pero se negó a conceder una ayuda de carácter extraordinario. Su contribución financiera se enmarcó más propiamente en los cauces de asistencia económica 
El ingreso de España en la Organización.....

bilateral desarrollados a partir de los pactos de 1953. Por otro lado, el crédito de la banca privada norteamericana estaba todavía en trámite de negociación y sería firmado en el mes de septiembre. Así pues, los fondos ligados directamente a la estabilización y utilizables de inmediato eran los 175 millones concedidos por los organismos internacionales, con los créditos de los bancos privados norteamericanos como reserva de segunda línea ${ }^{43}$.

El 20 de julio de 1959, tras garantizar el cumplimiento de las condiciones expuestas en el programa económico, España ingresó como miembro de pleno derecho de la OECE. Ese día, en su sesión $n^{\circ} .446$, el Consejo de la organización adoptaba un conjunto de resoluciones que hacían de España su decimoctavo miembro, y el primero que se incorporaba a ella después de su fundación ${ }^{44}$. Un día después se publicó el Decreto Ley de Ordenación Económica que ponía en marcha el Plan de Estabilización. En los meses siguientes fueron apareciendo las primeras disposiciones sobre listas de importaciones y transacciones invisibles liberalizadas, según las obligaciones contraídas por España con la OECE en materia de comercio exterior ${ }^{45}$. La aplicación del Plan de Estabilización había sido clave para franquear el acceso a esa organización. Análogamente, la intervención de la OECE había sido fundamental para hacer posible el cambio de rumbo económico, a través de los contactos de sus misiones de expertos con sus homólogos españoles, los informes elaborados sobre la situación de la economía española y las recomendaciones formuladas para su reorientación. Es más, continuó siendo de crucial importancia en la supervisión de la ejecución del plan y de sus efectos sobre la economía española.

Aún quedaba mucho camino por delante. Europa no se construía desde el idealismo, sino preferentemente desde el interés. Así tuvieron ocasión de comprobarlo los funcionarios españoles que intervinieron en la renegociación de los acuerdos bilaterales con once países de la OECE, desplegados desde abril de 1959 para acelerar el ingreso en la organización. Las gestiones estuvieron lejos de ser un camino de rosas: «El denominador común de las negociaciones con los países de la OECE ha sido su dureza, pues cada uno de ellos ha venido a Madrid con el propósito de cobrar en el terreno comercial el voto que en el terreno político había dado a favor de nuestro ingreso en aquel organismo, y ha pretendido aprovechar dicho ingreso para conquistar una situación de privilegio comercial en España ...». Según reconocía el informe la gran sorpresa había sido comprobar que la entrada en la OECE no había facilitado de forma decisiva la exportación de los productos agrícolas a Europa, pues la liberalización afectaba sobre 
todo a los productos industriales. En suma, la incorporación a la OECE no había supuesto un régimen de igualdad comercial ni resolvió el problema de la liberalización de las exportaciones, aunque sí que había favorecido la concesión de créditos y la transferibilidad de los pagos ${ }^{46}$.

Pese a no colmar todas las aspiraciones de los dirigentes españoles, es evidente que el ingreso en la OECE representó el primer jalón en la convergencia española hacia la integración europea y, por añadidura, un paso trascendental en el camino hacia la modernización económica del país. El Plan de Estabilización, que fue asociado a esa integración, modificó en pocos meses las perspectivas económicas. La rapidez de sus efectos sorprendió incluso a los observadores de las organizaciones internacionales.

El informe de la misión de la OECE desplazada a España en diciembre de 1959 para examinar la evolución del plan testimoniaba esa impresión favorable. Las medidas adoptadas respecto al presupuesto y al crédito habían eliminado el exceso de la demanda interior y permitido estabilizar los precios. No existía penuria de materias primas ni de productos semiterminados y la especulación desaparecía. La nueva paridad de la peseta se asentaba en los mercados internacionales. La balanza de pagos había mejorado sensiblemente. La escasez de divisas daba paso a un incremento sustancial de las reservas. La deuda exterior había sido consolidada. La recesión que se había producido era considerada casi inevitable, sería de corta duración y posibilitaría que la expansión económica posterior se realizara sobre bases sanas y duraderas. También se apuntaba la necesidad de emprender reformas estructurales complementarias en diversos aspectos de la reglamentación económica interna o en las inversiones extranjeras, además de acelerar la liberalización de las importaciones y de las transacciones invisibles. En el segundo semestre de 1960 la economía española superaba la recesión y comenzaba una fase de crecimiento. En esa nueva etapa las recomendaciones de la OECE insistirían en impulsar el libre juego de las fuerzas económicas ${ }^{47}$.

La situación internacional había resultado crucial para fomentar las tendencias proclives a un cambio de rumbo en la economía española, que la adaptase a los esquemas imperantes en las economías occidentales. Las resistencias a esa orientación no fueron desdeñables, pero los sectores convencidos de que era preciso tomar medidas para lograr la estabilidad interna, la globalización del comercio exterior y una flexibilización de las regulaciones del mercado interior, tuvieron en el contexto internacional «su mejor aliado, su elemento precipitante». ${ }^{48}$ Los movimientos integracionistas europeos y la declaración de convertibilidad de finales de 
1958 habían actuado como «el catalizador» de las medidas estabilizadoras y liberalizadoras de mediados de 1959. Esa renta de oportunidad fue aprovechada por los equipos de técnicos españoles favorables a la reorientación económica, que utilizaron las recomendaciones de las organizaciones internacionales para ofrecer argumentos «desde fuera» ${ }^{49}$.

La estabilización y la liberalización fueron impulsadas desde el exterior, por las presiones de los organismos internacionales y de Estados Unidos, y por la necesidad de contar con su asesoramiento y su ayuda económica para sortear la precaria situación de la balanza exterior española. La alternativa en 1959 era dejar de importar o suspender pagos, tal y como indicaba un destacado protagonista de aquel proceso: «la situación era virtualmente de suspensión de pagos exteriores por parte del I.E.M.E., ya que éste no podía ceder divisas ni para las importaciones más indispensables» ${ }^{50}$. Sin la asistencia y el estímulo exteriores es más que dudoso que el gobierno español de la época hubiera conseguido, por sí solo, situar al país en la senda del desarrollo económico y la modernización. La pertenencia a un espacio geográfico, económico y estratégico, o si se prefiere los dictados de la geopolítica, resultaron fundamentales para reubicar plenamente a España en los patrones de la economía capitalista occidental. Con once años de retraso, la España de Franco, relegada del Plan Marshall por sus antecedentes fascistas, iba a incorporarse al ciclo de crecimiento económico europeo alentado por aquel y a su principal instrumento de coordinación: la OECE.

\section{Notas}

\footnotetext{
* Este artículo se ha realizado en el marco del proyecto de investigación titulado El Ministerio de Asuntos Exteriores y la élite diplomática, 1936-1953, financiado por la Subdirección General de Formación y Promoción del Conocimiento (PB96-0914) del Ministerio de Educación y Cultura.

Las abreviaturas citadas en el texto corresponden a: AEF-MFCF: Archives économiques et financières-Ministère français du Commerce et Finances (Direction du Trésor); AGA-MAE: Archivo General de la Administración-Ministerio de Asuntos Exteriores; AGA-MT: Archivo General de la Administración-Ministerio de Trabajo; AMAE: Archivo del Ministerio de Asuntos Exteriores; AMFAE-DEF: Archives du Ministère français des Affaires Etrangères-Division Economique et Financière (Service de Coopération Economique); FRUS: Foreign Relations of United States; OEEC (OECE): Organisation for European Economic Cooperation-Historical Archives of the European Communities.

1 El texto integro se encuentra reproducido en Información Comercial Española 612-613 (agosto-septiembre, 1984), pp. 11-14.

2 TORTELLA, Gabriel: El desarrollo de la España contemporánea. Historia económica de los siglos XIX y XX, Madrid, Alianza Editorial, 1994, p. 281.
} 
3 Una argumentación más detallada sobre esos tres motivos explicativos del cambio en FUENTES QUINTANA, Enrique: «El Plan de Estabilización económica de 1959, veinticinco años después", Información Comercial Española, 612-613 (agosto-septiembre, 1984), pp. 25-30.

4 Sobre las condiciones que rodearon la exclusión española del Plan Marshall, vid. VIÑAS, Angel et alii: Política comercial exterior en España (1931-1975), Madrid, Banco Exterior de España, 1979, tomo 2, pp. 465-487; ViÑAS, Angel: Guerra, dinero, dictadura. Ayuda fascista y autarquía en la España de Franco, Barcelona, Crítica, 1984, pp. 265-287; GUIRAO, Fernando: Spain and the Reconstruction of Western Europe 1945-57. Challenge and Reponse, London \& New York, MacMillan Press and St. Martin Press, 1998; Delgado Gómez-Escalonilla, Lorenzo: "El régimen de Franco, el Plan Marshall y las potencias occidentales", en Tiempos de silencio. Actas del IV Encuentro de Investigadores del Franquismo, Valencia, Universitat de Valencia, 1999, pp. 488-495.

5 Para un marco general de las relaciones con Europa occidental en aquellos años vid. LA PORTE, María Teresa: La política europea del régimen de Franco 1957-1962, Pamplona, EUNSA, 1992; MORENO JUSTE, Antonio: Franquismo y construcción europea (1951-1962), Madrid, Tecnos, 1998.

6 Sobre las iniciativas tomadas en el terreno cultural vid. DelGado GómEz-EsCALONILLA, Lorenzo: «El régimen franquista y Europa: el papel de las relaciones culturales, 1945-1975", en La política exterior de España en el siglo XX, Madrid, UNED, 1997, pp. 415-440.

7 "Association of Spain in the work of the Organisation in matters of European inland transport", 16-IV-1954. OEEC, C. (54)109. "Secrétaire général adjoint -OECE0 au Directeur des Organisations Internationales du Ministère espagnol des Affaires Etrangères", 4-VIII-1954. OEEC, 411 (Spain, Association to OEEC working, 1954-1961. National Delegations). "Nombramiento representante español cerca de la OECE", 2VII-1954; "Constitución comité de enlace España-OECE», 31-VII-1954. AGA-MAE (Embajada de España en París, 1939-1971), 11551.

8 "Green Pool": Visit by MM. Mosquera and de Escoriaza», 10-VIII-1954; «Association de l'Espagne aux travaux de l'Organisation", 5-X-1954; "Note. Participation de l'Espagne aux travaux de l'Organisation", 17-XI-1954. OEEC, 411. "Minutes of the 265th Meeting", 9-XI-1954. OEEC, C/M(54)029. "Décision du Conseil relative à la poursuite des travaux de l'organisation dans le domaine de l'Agriculture et de l'Alimentation. Annexe: Projet d'accord entre l'Organisation Européenne de Coopération Économique et le Gouvernement espagnol rélatif à la participation de l'Espagne aux travaux de l'organisation interessant l'Agriculture et l'Alimentation", 17-I-1955. OEEC, C(54)326. "Agreement between the OEEC and the Spanish government concerning the participation of Spain in the work of the Organisation on questions relating to agriculture and food", 9-II-1955. OEEC, C(55)025. "Nota sobre el proyecto de participación de España a los trabajos de la OECE», 17-XI-1954; "Firma del Acuerdo entre España y la OECE», 28-I-1955. AGA-MAE, 11551. "Proceso para la integración del Pool Verde en la OECE y estatuto especial para España al producirse esta integración", 15-I-1955. AMAE, R-7650/1.

9 Su Presidente era Jaime Argüelles Armada, Subsecretario de Economía Exterior, y como Vicepresidente se nombró a Francisco Javier Elorza -Marqués de Nerva-, Consejero de Economía Exterior. OEEC, SGD(55)22. En octubre de 1956 se produjo un relevo en la vicepresidencia, incorporándose a la misma Eduardo de la Iglesia. En febrero de 1958 ocurrió otro tanto con la presidencia, que ocupó José Nuñez Iglesias. OEEC, 411. 
10 «Report Prepared by the Operations Coordinating Board. United States Policy toward Spain", 27-IV-1955. FRUS, 1955-1957, vol. XXVII, pp. 533-537.

11 «Consideraciones de orden político sobre el eventual ingreso de España en la OECE», 22-VI-1955. AGA-MAE, 11551. Se trata de un resumen del documento mucho más amplio elaborado por la Delegación española cerca de la OECE, "Informe sobre la eventual entrada de España en la OECE», 8-VII-1955. AMAE, R-5332/1.

12 Vid. VIÑAS, Angel et alii: Política comercial..., tomo 2, pp. 835-841.

13 "Participation of Spain in the study concerning research and exploitation of crude oil and natural gas on OEEC countries», 28-X-1955. OEEC, C(55)278. "Participation of Spain in the work of the Hides and Skins Committe. Final version", 8-XI-1955. OEEC, C(55)280.

14 "Admission de l'Espagne à l'OECE», 3-XI-1955; «L'Espagne et l'OECE», 3-XII1955. AMFAE-DEF (1945-1960, Espagne), vol. 371. «Résume de la discussion intervenue le jeudi 6 decembre entre les Chefs de Délégation au sujet de l'admission de l'Espagne à l'OECE», 14-XII-1955. OEEC, 411.

15 "Minutes of the 306th, 314th, 318th and 320th Meetings", 6-I, 17-II, 9-III y 14-III-1956. OEEC, C/M(56)001, C/M(56)009, C/M(56)013 y C/M(56)015. «Memorandum», 24-II-1956. AGA-MAE, 11551. «Espagne. Propositions du Président concernant la procedure à adopter pour l'enquête sur la situation économique de l'Espagne", 8III-1956. OEEC, CES/56/57. «Désignation des membres du Groupe de Travail chargé d'éffectuer une enquête sur la situation de l'Espagne», 27-III-1956. OEEC, CES/56/71. "L'Espagne et l'OECE», 13-II-1956; "Discussions officieuses du probleme espagnol à l'OECE lors de la session ministérielle», 25-II-1956; "Direction Générale des Affaires Economiques et Financières à l'Ambassade de France en Espagne», 27-II-1956; “Ambassade de France en Espagne à la Direction Générale des Affaires Economiques et Financières», 28-III-1956. AMFAE-DEF, vol. 371.

16 «Informe sobre la entrada de España en la OECE», 6-VII-1956. AMAE, R-5332/3. «Participation of Spain in the work of the Organisation. (Note by the Secretary of the Council)», 11-VII-1956. OEEC, C(56)192.

17 "Association of Spain in the Work of the Organisation. Report of the Special Working Party of the Council. Annex A: The Economic Situation of Spain. Annex B: Obligations of Membership", 17-VII-1956. OEEC, C(56)201 Annexes.

18 «Procès-verbal des 337ème, 341ème, 342ème et 343ème Séances», 31-VII, 5-X, 19-X y 26-X-1956. OEEC, C/M(56)032, C/M(56)036, C/M(56)037 y C/M(56)038. «Projet de résolution du Conseil concernant la création d'un Groupe de Travail chargé de préparer les modalités d'une association plus étendue avec l'Espagne", 17-X-1956. OEEC, CES/56/220. «Résolution du Conseil concernant la création d'un Groupe de Travail chargé de préciser les modalités de l'association de l'Espagne avec l'Organisation", 29-X-1956. OEEC, C(56)236. "Admission de l'Espagne à l'OECE", 28-VII, 2-VIII, 24-VIII y 1-X-1956; "Association de l'Espagne aux travaux de l'OECE», 8-X-1956. AMFAE-DEF, vol. 371. "Ingreso de España en la OECE», 2-VIII-1956. AGA-MAE (Embajada de España en París, 1939-1971), 11550. «Nota para el Sr. Ministro de Asuntos Exteriores: Resumen del desarrollo de las relaciones de España con la OECE», 21-IX-1956. AMAE, R-5332/2.

19 VIÑAS, Angel et alii: Política comercial..., tomo 2, pp. 849-855. «Partenza ambasciatore Lodge per gli Stati Uniti. Suoi colloqui con Ministri spagnoli Esteri e Commercio", 29-XI-1957. Archivio della Ambasciata d'Italia, Madrid.

20 "Association de l'Espagne aux travaux de l'Organisation. Déclaration du Président du Groupe de Travail $\mathrm{n}^{\circ} .18 \mathrm{du}$ Conseil à la réunion des Chefs de Délégations du vendredi 14 decembre 1956», 17-XII-1956. OEEC, CES/56/293. «Participation de 
l'Espagne aux travaux de l'Organisation sur la pénurie actuelle de pétrole en Europe", 19-XII-1956. OEEC, CES/56/289. «Minutes of the 350th Meeting», 21-XII-1956. OEEC, C/M(56)045. España participaba también para entonces en otros proyectos de la Agencia Europea de Productividad. «Participation de l'Espagne au Projet de "Condensés d'articles techniques" de l'Agence Européenne de Productivité», 20-VI-1956. OEEC, C(56)198.

21 «Mision technique à Madrid. Rapport établi à lintention du Groupe de Travail $\mathrm{n}^{\circ}$. $18 \mathrm{du}$ Conseil", 13-VI-1957. AEF-MFCF, B-10837. "Association de l'Espagne avec l'Organisation. Note du Président du Groupe de Travail nº. 18 du Conseil», 9-VII-1957. OEEC, C(57)157. Alemania, Dinamarca, Grecia, Irlanda, Noruega, Suecia, Suiza y Gran Bretaña ya aplicaban a España las mismas medidas de liberalización sobre las importaciones y las transacciones invisibles que a los otros países miembros. Islandia le concedía incluso un tratamiento más favorable. Italia y Países Bajos aplicaban una liberalización parcial, menor que con el resto de los países de la OECE. Francia sólo lo hacía en aspectos relativos a las transacciones invisibles. Portugal y Turquía no aplicaban ninguna medida de liberalización. «Extension à l'Espagne des mesures de liberation des echanges appliquées par les pays membres entre eux. (Note du Secrétaire du Conseil)», 16-X-1956. OEEC, CES/56/217.

22 «Relations entre l'Organisation et l'Espagne. Projet d'inscription au procès-verbal du Conseil», 10-IX-1957. AEF-MFCF, B-10837. «Procès-verbal de la 376ème Séance», 13-IX-1957. OEEC, C/M(57)026. «Acuerdo del Consejo de la OECE sobre la participación de España en los trabajos de la Organización», 14-IX-1957. AGA-MAE, 11551. «Resumen del desarrollo de las relaciones de España con la OECE», 21-IX-1957. AMAE, R-5332/2.

23 «Plan pour des negociations avec l'Espagne en vue d'arrangements multilateraux d'echanges et de paiements», 7-XI-1957. AEF-MFCF, B-10837. «Asociación de España con la OECE», 16-XI-1957. AMAE, R-5332/2.

24 «Proyecto de acuerdo de asociación de España con la OECE», 4-XII-1957. AGAMT, 18861. «Procès-verbal de la 391ème Séance», 20-XII-1957. OEEC, C/M(57)041. "Council Decision approving the draft Agreement between the Organisation and the Spanish government concerning the association of Spain with the work of the Organisation», 20-XII-1957. OEEC, C(57)265. «Procès-verbal de la 393ème Séance», 10-I-1958. OEEC, C/M(58)001. "Agreement between the OEEC and the Spanish government concerning the association of Spain with the work of the Organisation", 10-I-1958. OEEC, C(58)017. «Procès-verbal de la 405ème Séance», 18-IV-1958. OEEC, C/M(58)013. «Council Decision confirming the Agreement between the Organisation and the Spanish government concerning the association of Spain with the work of the Organisation", 18-IV-1958. OEEC, C(58)097.

25 «Telegram from the Embassy in Spain to the Department of State», 24-III-1958. FRUS, 1958-1960, vol. VII, part 2, pp. 702-703. En esa comunicación se recordaban iniciativas de esta índole ya expuestas durante el año anterior.

26 «Embajada de España en París al Ministerio de Negocios Extranjeros», 7-XII1957; «Memorandum de la Embajada de España en París», 27-II-1958; «Ingreso de España en el Comité Intergubernamental OECE», 16-VII-1958. AGA-MAE, 11550. «L'Espagne et la zone de libre échange», 20 y 27-XII-1957; «Embajada de España en París al Ministerio de Negocios Extranjeros», 22-VII-1958; «Participation de l’Espagne aux travaux du Comité Intergouvernemental», 8-VIII-1958; “Telegramme. DiplomatieParis», 26-IX-1958; "Admission de l'Espagne aux travaux du Comité Intergouvernemental", 27-X-1958; "Participation de l'Espagne aux travaux du Comité Intergouvernemental», 8-XI-1958; “Ministère des Affaires Etrangères à l'Ambassade 
d'Espagne à Paris», 18-XI-1958. AMFAE-DEF (1945-1960, Zone de libre échange, Espagne), vol. 773 .

27 «Participación española en el Grupo Atómico y en la Sociedad Internacional "Eurochemic" de la OECE», 18-XI-1957. AGA-MT, 18861. "Participation éventuelle de l'Espagne aux travaux de l'OECE dans le domaine de l'Energie Nucléaire", 10-III-1958; "Association de l'Espagne aux travaux de l'Agence Européenne pour l'Energie Nucléaire», 20-III-1958; «Association de l'Espagne aux travaux de l'Agence Européenne pour l'Energie Nucléaire. (Note du Secrétaire du Conseil)», 22-III-1958; "Association de l'Espagne aux travaux de l'Agence Européenne pour l'Energie Nucléaire», 14-X-1958. OEEC, 411. "Association de l'Espagne à l'Agence Européenne pour l'Energie Nucléaire. (Rapport du Groupe de Travail n. 18 au Conseil)», 13-V-1958. OEEC, CES/8.075.

28 MUNS, Joaquín: Historia de las relaciones entre España y el Fondo Monetario Internacional 1958-1982, Madrid, Alianza Editorial/Banco de España, 1986, pp. 23-27.

29 "Working Party n'. 18 of the Council. Minutes of the 17th Meeting», 11-III-1958. OEEC, 411. «La OECE cumple 10 años. Castiella viaja a París representando a España en la sesión conmemorativa del Consejo». SP, IV-1958, pp. 23-27 (en AGA-MAE, 11550).

30 «Intelligence Report. Present and Future Spanish Foreign Policy», 7-VIII-1958. FRUS, 1958-1960, vol. VII, part 2, pp. 710-720.

31 «Managing Board of the European Payments Union. Association of Spain with the Work of the Organisation. (Notes by the Secretariat)», 31-VIII y 11-IX-1958; "European Payments Union. Association of Spain with the Work of the Organisation", 25 y 30-X-1958; "Payments Arrangements with Spain. Summary of Replies to the Questionnaire in TFD.758. (Note by the Secretariat)», 28-X-1958; “Managing Board of the European Payments Union. Some Questions to be put to the Representatives of Spain", 19-XI-1958. OEEC, 368 (Association of Spain with OEEC, 1958-1959). "Association of Spain with the Work of the Organisation. (Note by the Secretariat of the Working Party)», 18-IX-1958; "Memorandum submitted by the Spanish Delegation to the OEEC», 19-XII-1958. OEEC, 411. "Nota a la Embajada norteamericana en España», 20-IX-1958; "Nota sobre las gestiones realizadas cerca de la OECE con relación al Plan de Multilateralización de Comercio y Pagos», 7-I-1959. AMAE, R-5884/5 y R-5884/1. "Memorandum of Conversation. US-Spanish Economic Relations», 28-XI-1958. FRUS, 1958-1960, vol. VII, part 2, pp. 720-723. «European Payments Union. Memorandum submitted by the Spanish authorities concerning Spain's foreign exchange regime», 8-XII-1958. OEEC, 581 (Admission of Spain to OEEC, 1958-1959. Archives of M. Fay). "Arrangements multilateraux d'echanges et de paiements proposes par les autorités espagnoles", 19-II-1959. AEF-MFCF, B-10837.

32 Vid. GonZÁlez GoNZÁLEZ, Manuel J.: La economía política del franquismo (19401970). Dirigismo, mercado y planificación, Madrid, Tecnos, 1979, pp. 165-181.

33 "Board of Management of the European Monetary Agreement steering Board for Trade. Economic Situation of Spain. Confidential report by the Secretariat", 7-I-1959. OEEC, 581. Economic conditions in member and associated countries of the OEEC. Spain 1958, Paris, OEEC, 1958. «Direction des Affaires Economiques et Financières à l'Ambassade de France en Espagne», 23-I-1959. AMFAE-DEF, vol. 371.

34 «Procès-verbal de la 428ème Séance», 30-I-1959. OEEC, C/M(59)003.

35 "IMF. Spain. Staff Report and Recommendations - 1958 Consultations", 22IV-1959. AEF-MFCF, B-10852.

36 El texto figura, bajo el título de "Propuesta de un Plan de Estabilización", II-1959, en SARDÁ DeXeUS, Juan: Escritos (1948-1980), Madrid, Banco de España, 1987, pp. 371-373. El proceso de elaboración y negociación del Plan de Estabilización 
ha sido ampliamente tratado por la literatura económica. Junto al libro de Sardá antes citado, vid. entre otros VIÑAS, Angel et alii: Política comercial..., tomo 3, pp. 1018-1167; GoNZÁLEZ GoNZÁLEZ, Manuel J.: La economía política ..., pp. 194-205; MUNS, Joaquín: Historia de las relaciones ..., pp. 28-39; y FUENTES QUINTANA, Enrique: «El Plan de Estabilización...", pp. 32-38.

37 «Procès-verbal de la 431ème Séance», 17-II-1959. OEEC, C/M(59)006.

38 "Memorandum of Conversation. Discussion of Questions Affecting OEEC», 22IV-1959. FRUS, 1958-1960, vol. VII, part 1, pp. 110-111. "Discussions de la Mission du Secrétariat à Madrid avec les représentants du Gouvernement espagnol", 4-V-1959; «Finance for Spain», 11-V-1959; "Notes on Mission to Madrid», 11/15-V-1959; "Programa español de estabilización económica. Memorandum para la OECE y el FMI", 27-V-1959; "Programme de stabilisation espagnole - Commentaires", 28/29-V-1959. OEEC, 581.

39 "Note by the Spanish Delegation. (Cover Note by the Secretary of the Council)", 15-V-1959. OEEC, CES/9.056. «Espagne. Projet d'inscription au procès-verbal du Conseil», 25-V-1959. OEEC, CES/9.061. "Minutes of the 438th Meeting", 29-V-1959. OEEC, C/M(59)13. "Accesion de l'Espagne à l'OECE en qualité de membre de plein exercice», 30-V-1959; “Note pour le Premier Ministre. Espagne», 2-VI-1959. AMFAE-DEF, vol. 371.

40 «Espagne. Problèmes commerciaux. Questions à examiner avec les autorites espagnoles et qui doivent être mentionnées dans leur memorandum sur le programme d'assainissement ou dans les annexes", 2-VI-1959; "Rémarques sur le Programme Espagnol de Stabilisation", 4-VI-1959; "Suggestions for changes in the clarifications of the Spanish Programme», 14-VI-1959. OEEC, 581. "Programa de estabilización económica de España: Breve resumen de la situación de la negociación con los representantes de la OECE y el FMI», 20-VI-1959. AMAE, R-5884/6. «Problemes techniques que poserait l'adhésion de l'Espagne a l'AME (Note du Secrétariat)", 22-VI-1959. OEEC, AMC(59)39. «Rapport de la Mission envoyée en Espagne en juin 1959 sur le Programme de Stabilisation Economique du Gouvernement espagnol. Annexe: Evolutions relatives à la balance commerciale pour 1959-1960", 1-VII-1959. OEEC, CES/9.082.

41 «Memorandum from Spanish government to the IMF and the OEEC. Annexes concerning countries with wich Spain will maintain bilateral trade and payments arrangements", 4-VII-1959. OEEC, C(59)181. "Comité de Direction des Echanges. Notification speciale de l'Espagne», 4-VII-1959. OEEC, CES/9.085.

42 «Rapport du Comité Directeur de l'AME sur le Programme de Stabilisation de l'Espagne et sa demande de participation à l'OECE et à l'AME", 2-VII-1959. OEEC, CES/9.083. «Rapport du Comité de Direction des Echanges sur le Programme de Stabilisation de l'Espagne et sur les conditions de l'adhésion de l'Espagne à l'OECE», 3-VII-1959. OEEC, CES/9.086. "Spain's Membership in the OEEC. (Note by the Legal Adviser)», 6-VII-1959. OEEC, CES/9.087. «Report by the Economic Committe on Spain's Stabilisation Programme», 15-VII-1959. OEEC, C(59)186. "Commentaires du Comité Mixte des Echanges et des Paiements Intra-européens sur les rapports du Comité Directeur de l'AME et du Comité de Direction des Échanges relatifs aux conditions de l'accession de l'Espagne à l'OECE», 16-VII-1959. OEEC, C(59)185. "Rapport du Comité Directeur de l'AME sur certaines conditions de l'adhésion de l'Espagne à l'AME et sur l'octroi d'une assistance financière a l'Espagne», 16-VII-1959. OEEC, C(59)187.

43 "Memorandum of Conversation. Spanish Stabilisation Program", 9-VII-1959. FRUS, 1958-1960, vol. VII, part 2, pp. 729-732. «Aide du Gouvernement américain et du Fonds Monétaire International à l'Espagne», 23-VII-1959; "De l'admission de l'Espagne à l'OECE et du plan de redressement économique», 27-VII-1959. AMFAE-DEF, 


\section{El ingreso de España en la Organización.....}

vol. 371. Sobre la actuación del FMI vid. "Spain: Economic Stabilisation Program», 8-VII-1959; «1958 Consultations. Suplementary Background Information», 13-VII-1959; «Spain. Use of Fund Resources», 15-VII-1959. AEF-MFCF, B-10852.

44 «Procès-verbal de la 446ème Séance», 17/20-VII-1959. OEEC, C/M(59)021. «Notifications et instruments relatifs à l'adhésion de l'Espagne à la Convention du 16 avril 1948 et à l'Accord Monetaire Européen». OEEC, C(59)188. "Décision du Conseil relative à l'adhésion de l'Espagne á la Convention de Coopération Économique Européenne». OEEC, C(59)189. "Décision du Conseil relative à l'adhésion de l'Espagne à l'Accord Monetaire Européen». OEEC, C(59)190. «Décision du Conseil portant amendement à l'Accord Monetaire Européen à la suite de l'adhésion de l'Espagne». OEEC, C(59)191. "Décision du Conseil relative à l'application à l'Espagne du Code de la Libération et de décisions connexes». OEEC, C(59)192. "Council Resolution concerning the carrying out, review and reinforcement of Spain's Stabilisation Programme». OEEC, C(59)193. “Décision du Conseil relative à l'assistance financière à l'Espagne». OEEC, C(59)195. «Décision du Conseil relative à l'application à l'Espagne des décisions du Conseil adoptées antérieurement à l'adhésion de l'Espagne á la Convention de Coopération Économique Européenne». OEEC, C(59)196.

45 «Report by the Steering Board for Trade on the 1. instalment of global quotas proposed by the Spanish government. Annex: Memorandum by the Spanish government", 20-VII-1959. OEEC, C(59)180. «Spain: comments of the Joint Trade and Intra European Payments Committe on the report by the Steering Board for Trade on the 1. instalment of global quotas proposed by the Spanish government", 23-VII-1959. OEEC, C(59)211. "Council Resolution on the establishment by Spain of a 1. instalment of global quotas", 30-VII-1959. OEEC, C(59)212. «Measures of liberalisation of invisible transactions taken and about to be taken by Spain in conformity with the Spanish Stabilisation Programme. Addendum", 23-X-1959. OEEC, C(59)243. "Council Resolution on the establishment by Spain of a 2. instalment of global quotas", 22-XII-1959. OEEC, C(59)295.

46 "Memoria de la Dirección General de Relaciones Económicas", 30-VI-1960. AMAE, R-4450/14.

47 «Execution du Programme de Stabilisation du gouvernement espagnol. Rapport du Comité Directeur de l'Accord Monetaire Européen. Annexe I: Rapport de la mission qui s'est rendue en Espagne en decembre 1959 en vue d'étudier la mise en oeuvre du Programme de Stabilisation de l'Espagne et les problemes d'avenir", 19-I-1960. OEEC, C(60)018. «Rapport du Comité Economique sur l'exécution du Programme de Stabilisation du gouvernement espagnol», 27-I-1960. OEEC, C(60)026. «Decision of the Council concerning the carrying out of Spain's Stabilisation Programme and Financial Assistance to Spain", 15-II-1960. OEEC, C(60)39. "Examen económico España», 27-VI-1960. AGA-MT, 18861.

48 GARCÍA DELGADO, José Luis: “La industrialización y el desarrollo económico e España durante el franquismo", en La economía española en el siglo XX. Una perspectiva histórica, Barcelona, Ariel, 1987, p. 175.

49 Vid. Ullastres CAlvó, Alberto: «El Plan de estabilización de la economía española: realizaciones y perspectivas", en Trece economistas españoles ante la economía española, Barcelona, 1975, p. 72; y VARELA, Manuel: «El Plan de Estabilización como yo lo recuerdo", Información Comercial Española, 676-677 (diciembre 1989-enero 1990), pp. 48 y ss.

50 SARDÁ Dexeus, Juan: Escritos..., p. 333. Vid. también «National Security Council Report. Statement of U.S. Policy toward Spain», 5-X-1960. FRUS, 1958-1960, vol. VII, part 2, pp. 785-793. 